九州大学学術情報リポジトリ

Kyushu University Institutional Repository

\title{
Tensile fracture testing and energy evaluation of a light-cured composite resin
}

Arakawa, Kazuo

Research Institute for Applied Mechanics, Kyushu University

Kato, Masaru

Research Institute for Applied Mechanics, Kyushu University

Mada, Toshiro

Research Institute for Applied Mechanics, Kyushu University

http://hdl. hand le. net/2324/26480

出版情報：Polymer Testing. 29 (1)，pp.1-6，2010-02-01. Elsevier バージョン：

権利関係: (C) 2009 Elsevier Ltd. 


\title{
Tensile fracture testing and energy evaluation of a light-cured composite resin
}

\author{
Kazuo Arakawa*, Masaru Kato, and Toshio Mada \\ Research Institute for Applied Mechanics, Kyushu University \\ 6-1 Kasuga-koen, Kasuga-shi, Fukuoka 816-8580, Japan \\ "Corresponding author, E-mail: k.arakaw @riam.kyushu-u.ac.jp \\ Tel: 81-92-583-7761, Fax: 81-92-593-3947
}

\begin{abstract}
The brittle fracture of a light-cured composite resin used in dental restoration was examined using a high-speed extensometer, consisting of an optical fiber and a position-sensing detector (PSD). Single-edge-cracked specimens for tensile testing were fabricated by packing the composite between two rectangular plates of polymethyl methacrylate (PMMA). In order to study the dynamic effect of brittle fracture and the nonelastic effect of the material, the specimens were pin-loaded with a special jig so that they could split and fly apart in the loading direction after fracture. The flying height and residual deformation of the split specimen were measured to estimate the elastic energy $E_{\mathrm{e}}$ and nonelastic energy $E_{\mathrm{n}}$, respectively. The fracture energy $E_{\mathrm{f}}$ required to create a new fracture surface was obtained by subtracting $E_{\mathrm{e}}$ and $E_{\mathrm{n}}$ from the external work $U_{\mathrm{ex}}$ applied to the specimen. The results showed that the ratio $E_{\mathrm{f}} / U_{\mathrm{ex}}$ was about $32 \%$ for the composite specimen over a wide range of the fracture load, while it was about $45 \%$ for the PMMA specimen. The energy release rate $G_{\mathrm{f}}$ was also estimated using $E_{\mathrm{f}}$. The results indicated that, although $G_{\mathrm{f}}$ increased with the fracture load, the increasing slope for the composite specimen was smaller than that of the PMMA specimen.
\end{abstract}

Keywords: Fracture testing; Light-cured resin composite; PMMA; Brittle fracture; Elastic energy; Nonelastic energy; Fracture energy; Energy release rate; High-speed extensometer 


\section{Introduction}

Light-cured composite resins are widely used in dental restoration due to their ease of handling and aesthetic appearance. However, their mechanical strength and resistance to fracture differ markedly from metals traditionally used in restoration, creating a need to develop stronger and more reliable resin composites. In particular, the fracture behavior of composites needs to be carefully assessed to ensure their mechanical reliability. Fracture toughness is usually evaluated in terms of elastic fracture mechanical theory by measuring the crack length and the load or external work applied to a tensile-stressed or bending specimen. Several different types of specimen geometries and experimental methods have been proposed for fracture toughness evaluation of composites [1-4]. However, problems exist in both the light curing procedure as well as the inherent brittleness of the cured material that results from the large content of inorganic powders and fillers, that make it difficult to fabricate standard-sized composite specimens such as are required for fracture toughness evaluation. In addition, most polymers exhibit some nonelastic effects from viscoelastic and plastic deformation [5]. Brittle fracture also causes dynamic or inertia effects when a crack propagates dynamically within the specimen, as is commonly the case [6-25]. These effects also need to be taken into account when evaluating the fracture toughness of brittle materials. Nonetheless, quantitative appraisals of both effects on fracture toughness have seldom been undertaken due to the difficulties inherent in the experimental techniques currently used.

We have explored these issues by measuring brittle fracture in polymers using a tensile loading device we have developed [26-30]. This device consists of a high-speed extensometer that allows quantitative measurements to be made of the static and dynamic displacements near the crack position in single edge-cracked specimens. The elastic energy stored in the specimens was evaluated by determining the flying height of the half specimen following fracture. The dynamic response and residual deformation of the specimen were then measured to evaluate the dynamic and nonelastic effects. The external work applied to the specimen was partitioned into three components: the elastic energy, nonelastic energy, and fracture energy required to create a new fracture surface. The energy release rate for crack propagation was similarly evaluated by 
using these parameters and indicated that the dynamic and nonelastic effects play important roles in understanding brittle fracture behavior [26-30].

In this study, we evaluated the proposed experimental procedure using a light-cured resin composite. As outlined above, this material presents a problem in fabricating standard-sized specimens due to both light curing procedures and resulting brittleness. To obviate these difficulties, we fabricated a novel type of single edge-cracked specimen by packing the composite between two rectangular PMMA plates. The nonelastic energy $E_{\mathrm{n}}$ arising from viscoelastic and plastic deformation was then measured using a high-speed extensometer that consisted of an optical fiber and a position-sensing detector (PSD). The elastic energy $E_{\mathrm{e}}$ was calculated from the kinetic energy of the split specimen by measuring the flying height following fracture. The external work $U_{\mathrm{ex}}$ was determined from the load and displacement applied to the specimen, and the displacement near the crack was obtained from the PSD. By subtracting $E_{\mathrm{e}}$ and $E_{\mathrm{n}}$ from $U_{\mathrm{ex}}$, we could obtain the fracture energy $E_{\mathrm{f}}$ required to create the new fracture surface. For a fracture surface $A_{\mathrm{s}}$, the energy release rate was evaluated using $G_{\mathrm{f}}=E_{\mathrm{f}} / A_{\mathrm{s}}$ and correlated with the fracture load of the specimen. This paper discusses the applicability of the experimental method to light-cured resin composites by comparing results with those of reference PMMA specimens.

\section{Specimen material and experimental methods}

The light-cured resin composite used in this experiment was Clearfil AP-X, supplied by Kuraray Medical, Ltd. This material is a cross-linked acrylic resin composed of about $85 \mathrm{wt} \%$ inorganic powders and fillers. It is widely used as a dental restorative material in clinical practice. To overcome the problems of fabricating standard-sized specimens from this material, as outlined above, our specimens had the geometry shown in Fig. 1(a), where the composite was packed between two rectangular plates of PMMA. We used PMMA because it has similar properties to the composite and adheres readily to the resin.

The specimens consisted of two rectangular PMMA plates (Sumipex E), $3 \mathrm{~mm}$ thick, 20 mm wide, and $90 \mathrm{~mm}$ long. Clearfil Tri-S Bond bonding agent (Kuraray Medical, Ltd.) was applied to the end surfaces of the plates and irradiated using a Morita Jetlite 3000 light unit to 
cure the agent. The two plates were directionally aligned using two frames on a transparent $5 \mathrm{~mm}$ thick PMMA plate with a $10 \mathrm{~mm}$ clearance gap, and the composite was packed into the gap and irradiated with the light.

To prevent specimen curvature following the curing, the composite was irradiated eight times alternately from the top and bottom (four times of $5 \mathrm{~s}$ duration and four times of $10 \mathrm{~s}$ duration) followed by a further $10 \mathrm{~s}$ upon removal of the frames. The surface of the composite was then ground and polished flat. Each specimen was stored for $24 \mathrm{hrs}$ in air at room temperature. The PMMA specimen shown in Fig. 1(b) was made to provide a comparison with the composite specimen.

The experimental procedure is illustrated in Fig. 2. The lower portion of the specimen was clamped rigidly and the upper part tightly confined with steel plate grips and a pin-shaped bolt and nut to satisfy the symmetry requirements. The specimen was then loaded at the pin. Fracture loading of the specimens was initiated at sharp pre-cracks of differing lengths ranging from 2 to $7 \mathrm{~mm}$ made by tapping a fresh razor blade into a pre-machined saw-cut on the specimen edge. A load was then introduced using a special loading jig consisting of four steel bars, as shown in Fig. 3. The shape of the jig allowed the specimen to split and fly apart in the loading direction after fracture. The flying height was recorded with a thin flexible paper pipe $(0.3 \mathrm{~g})$ inserted between the bars. The pipe rose with the split specimen $(30 \mathrm{~g})$ and stopped at the highest position attained by the uppermost part of the specimen due to friction between the pipe and the bars. This provided an estimate of the elastic energy contained in the specimen. In this study, the elastic energy in the jig was disregarded due to its far greater stiffness compared to the specimens. All specimens were tested under a displacement-controlled condition using a tensile testing machine, with tests performed at room temperature and at a constant crosshead rate of $1 \mathrm{~mm} / \mathrm{min}$.

Figure 2 also shows the configuration used to determine the displacement measurements of the loading point and the region beneath the pre-crack position, i.e., the centerline of the specimen. The loading point displacement was measured with the tensile testing machine, while the displacement near the pre-crack was determined from the optical fiber and PSD (SiTek Electro Optics) [26-30]. In this experiment, the fiber was attached at a point $2 \mathrm{~mm}$ from 
the pre-crack to avoid any damage arising from dynamic crack propagation. A laser diode provided the light source and an amplifier and digital wave memory recorded the output signals from the PSD. The PSD is an optoelectronic device that converts an incident light spot into continuous position data due to the lateral photo effect, and has a frequency response of $100 \mathrm{kHz}$. As a consequence, it allowed both static and dynamic displacements to be measured.

\section{Experimental results}

Figure 4 shows a typical load $P$ versus displacement $\delta$ diagram for a composite specimen determined from the tensile testing machine. As shown in the figure, $P$ increased almost linearly with $\delta$, but then dropped abruptly at $P_{\mathrm{c}}$ and $\delta_{\mathrm{c}}$, the critical values related to dynamic fracture initiation in the specimen. The $P-\delta$ diagram was partitioned into three regions, as discussed in subsequent sections.

To examine the residual displacement after fracture, the relationship between $\delta^{\prime}$ near the pre-crack and the time $t$ was recorded as a sampling rate $\Delta t=1 \mu \mathrm{s}$. Figure 5 shows that following fracture $\delta^{\prime}$ exhibited a damped oscillation behavior that fluctuated about $\delta_{\mathrm{n}}^{\prime}$. This indicates that there was a residual displacement during the oscillation owing to nonelastic deformation of the material. $\delta_{n}^{\prime}$ was ascertained first by determining the midpoints of the initial two oscillations. The intersection of a straight line between these two points and the line of the curve falling from $\delta_{c}^{\prime}$ was taken as the residual displacement $\delta_{n}^{\prime}$ of the split specimen. Then $\delta_{n}^{\prime}$ was corrected to obtain the value $\delta_{\mathrm{n}}$ at the centerline of the specimen by using the position of the optical fiber on the specimen. Figure 6 shows $\delta_{\mathrm{n}}$ as a function of the critical load $P_{\mathrm{c}}$. Since $\delta_{\mathrm{n}}$ for the two materials increased with $P_{\mathrm{c}}$, this implies that $\delta_{\mathrm{n}}$ increased with the critical load of the specimen. Further, there was a difference between the two values of $\delta_{\mathrm{n}}$ obtained from the composite and from the PMMA specimen for a given $P_{\mathrm{c}}$.

Figure 7 shows the flying height $H_{\mathrm{e}}$ of the split specimen as a function of the critical load $P_{\mathrm{c}}$. Although the data are scattered, $H_{\mathrm{e}}$ for the composite and PMMA specimens increased with $P_{\mathrm{c}}$ so as to imply that an increase in fracture load generated elastic energy in the specimen and hence an increase in flying height. 


\section{Definition of fracture energy}

The nonlinearity in the $P-\delta$ diagram for both materials is not significant (see Fig. 4). Hence, the external work $U_{\text {ex }}$ applied to a specimen can be determined as:

$$
U_{\mathrm{ex}}=P_{\mathrm{c}} \delta_{\mathrm{d}} / 2 .
$$

This analysis assumes that $U_{\mathrm{ex}}$ can be partitioned into the three regions shown in Fig. 4:

$$
U_{\mathrm{ex}}=E_{\mathrm{f}}+E_{\mathrm{e}}+E_{\mathrm{n}}
$$

where $E_{\mathrm{f}}$ is the fracture energy created for half the new surfaces, $E_{\mathrm{e}}$ is the specimen's elastic energy, and $E_{\mathrm{n}}$ is the nonelastic energy arising from the specimen's viscoelastic and plastic deformation [26-30].

Assumptions were made in determining $E_{\mathrm{e}}$ and $E_{\mathrm{n}}$. First, we assumed that $E_{\mathrm{e}}$ was converted into the kinetic energy following specimen fracture. Second, we assumed that the change from $P_{\mathrm{c}}$ to $\delta_{\mathrm{e}}$ or $\delta_{\mathrm{n}}$ was elastic since the material's viscosity can be neglected during dynamic crack propagation (see Fig. 4) [22, 23]. Hence:

$$
\frac{E_{\mathrm{e}}}{U_{\mathrm{ex}}}=\frac{\left(\delta_{\mathrm{e}}-\delta_{\mathrm{n}}\right)}{\delta_{\mathrm{c}}}, \quad \frac{E_{\mathrm{n}}}{U_{\mathrm{ex}}}=\frac{\delta_{\mathrm{n}}}{\delta_{\mathrm{c}}}
$$

\section{Evaluation of fracture energies}

The nonelastic energy $E_{\mathrm{n}}$ was evaluated using Eq. (3) and the nonelastic displacement $\delta_{\mathrm{n}}$ determined for both the composite and PMMA specimens (see Fig. 6). Figure 8 shows the ratio $E_{\mathrm{n}} / U_{\mathrm{ex}}$ as a function of the critical load $P_{\mathrm{c}} \cdot E_{\mathrm{n}} / U_{\mathrm{ex}}$ of the composite specimen increased almost linearly with $P_{\mathrm{c}}$. It reached about $38 \%$ in the region of small $P_{\mathrm{c}}$, and about $57 \%$ in the region of large $P_{\mathrm{c}}$, while $E_{\mathrm{n}} / U_{\mathrm{ex}}$ for the PMMA specimen remained almost constant at $40 \%$ over a wide $P_{\mathrm{c}}$ range.

From the flying height $H_{\mathrm{e}}$ of the split specimen after fracture (see Fig. 7), the elastic energy $E_{\mathrm{e}}$ in the specimen could be evaluated as:

$$
E_{\mathrm{e}}=m g H_{\mathrm{e}}
$$

where $m$ is the total mass of half the specimen, loading pin, grip, and paper pipe, and $g$ is the gravitational acceleration. Figure 8 also shows the ratio $E_{\mathrm{e}} / U_{\mathrm{ex}}$ as a function of the critical load $P_{\mathrm{c}}$. The value of $E_{\mathrm{e}} / U_{\mathrm{ex}}$ for the composite specimen was about $27 \%$ in the region of small $P_{\mathrm{c}}$, 
and about $12 \%$ in the region of large $P_{\mathrm{c}}$, with $E_{\mathrm{e}} / U_{\mathrm{ex}}$ for the PMMA specimen remaining almost constant at $14 \%$ over a wide $P_{\mathrm{c}}$ range. In this analysis, we were unable to make a quantitative evaluation of the energy loss caused by elastic wave generation from the crack tip and the friction between the loading jig and the paper pipe or split specimen; this energy loss was disregarded. Hence, the elastic energy determined from Eq. (4) may have been underestimated.

The fracture energy $E_{\mathrm{f}}$ was evaluated from Eq. (2) by substituting the elastic and nonelastic energies. Figure 9 shows the energy ratio $E_{\mathrm{f}} / U_{\mathrm{ex}}$ as a function of the critical load $P_{\mathrm{c}}$. Although there was a scattering of $E_{\mathrm{f}} / U_{\mathrm{ex}}$ data for the composite specimen, the value remained almost constant at $32 \%$ over a wide $P_{\mathrm{c}}$ range. A similar situation existed for the PMMA specimen, with $E_{\mathrm{f}} / U_{\text {ex }}$ remaining nearly constant at $45 \%$. This suggests that $E_{\mathrm{f}} / U_{\text {ex }}$ was not strongly influenced by the fracture conditions in terms of parameters such as $P_{\mathrm{c}}, \delta_{\mathrm{c}}$, or $U_{\mathrm{ex}}$.

The energy release rate $G_{\mathrm{f}}$ was estimated from:

$$
G_{\mathrm{f}}=E_{\mathrm{f}} / A_{\mathrm{s}}
$$

where $A_{\mathrm{s}}$ is half the area of the total fracture surface. Figure 10 shows $G_{\mathrm{f}}$ as a function of $P_{\mathrm{c}} . G_{\mathrm{f}}$ increased in both materials with $P_{\mathrm{c}}$, although the slope for the composite specimen was less than that of the PMMA specimen. This difference supports the validity of both the present testing method and of the specimen geometry employed, particularly given the difference in fracture behavior of the two materials. It is our intention to explore this effect in more detail in our future work by investigating the crack velocity during crack propagation, given that the energy release rate also depends on the velocity.

\section{Conclusions}

The fracture behavior of a light-cured resin composite was examined using single-edge-cracked tensile specimens fabricated by packing the composite between two rectangular PMMA plates. From the load and displacement relationship, the external work $U_{\text {ex }}$ applied to the specimen was used to establish the elastic energy $E_{\mathrm{e}}$, nonelastic energy $E_{\mathrm{n}}$ due to viscoelastic and plastic deformation, and fracture energy $E_{\mathrm{f}}$ involved in creating a new fracture surface $A_{\mathrm{s}}$. The energy release rate was then estimated from $G_{\mathrm{f}}=E_{\mathrm{f}} / A_{\mathrm{s}}$. The energy ratios $E_{\mathrm{n}} / U_{\mathrm{ex}}$, 
$E_{\mathrm{e}} / U_{\mathrm{ex}}, E_{\mathrm{f}} / U_{\mathrm{ex}}$, and $G_{\mathrm{f}}$ for the composite specimen were then correlated with the fracture load $P_{\mathrm{c}}$, and compared with those for PMMA specimens. The results showed the following.

(1) $E_{\mathrm{e}} / U_{\mathrm{ex}}$ for the composite specimen was about $27 \%$ in the region of small $P_{\mathrm{c}}$, and about $12 \%$ in the region of large $P_{\mathrm{c}}$, while $E_{\mathrm{e}} / U_{\mathrm{ex}}$ for the PMMA specimen remained almost constant at $14 \%$ over a wide $P_{\mathrm{c}}$ range.

(2) $E_{\mathrm{n}} / U_{\mathrm{ex}}$ for the composite specimen was about $38 \%$ in the region of small $P_{\mathrm{c}}$, and about $57 \%$ in the region of large $P_{\mathrm{c}}$, while $E_{\mathrm{n}} / U_{\mathrm{ex}}$ for the PMMA specimen remained almost constant at $40 \%$ over a wide $P_{\mathrm{c}}$ range.

(3) $E_{\mathrm{f}} / U_{\text {ex }}$ for the composite specimen was about $32 \%$ over a wide range of $P_{\mathrm{c}}$, but was about $45 \%$ for the PMMA specimen.

(4) $G_{\mathrm{f}}$ for both materials increased with $P_{\mathrm{c}}$, but the slope of the composite specimen was less than that of the PMMA specimen.

\section{Acknowledgments}

The authors would like to express their gratitude to Kuraray medical Ltd. for supplying materials and a curing unit. They also grateful to Mr. S. Yamaguchi and Mr. Y. Takahata from Kuraray medical Ltd. for their useful advice. This work was supported by the Japanese Ministry of Education, Culture, Sports, Science and Technology, as part of the "HighlyFunctional Interfaces Science: Innovation of Biomaterials with Highly Functional Interface to Host and Parasite" project.

\section{References}

[1] R.E. Kovarik, J.W. Ergle, C.W. Fairhurst, Effects of specimen geometry on the measurement of fracture toughness, Dent. Mater. 7 (1991) 166-169.

[2] Y. Higo, D. Damri, S. Nunomura, K. Kumada, N. Sawa, K. Hanaoka, T. Teranaka, T. Iwamoto, The fracture toughness characteristics of three dental composite resins, Biomed. Mater. Engng. 1 (1991) 223-231.

[3] D.J. Indrani, W.D. Cook, F. Televantos, M.J. Tyas, K. Harcourt, Fracture toughness of water-aged resin composite restorative materials, Dent. Mater. 11 (1995) 201-207.

[4] L.A. Knobloch, R.E. Kerby, R. Seghi, J.S. Berlin, N. Clelland, Fracture toughness of packable and conventional composite materials, J. Prosthet. Dent. 88-3 (2002) 307-313. 
[5] J.G. Williams, Fracture Mechanics of Polymers, Ellis Horwood Limited, Chichester, 1984.

[6] A.S. Kobayashi, Handbook on Experimental Mechanics, Prentice-Hall, Inc., Englewood Cliffs, New Jersey, 1987.

[7] K. Ravi-Chandar, Experimental challenges in the investigation of dynamic fracture of brittle materials, Bouchaud, et al. (Eds), Physical Aspects of Fracture, E. Kluwer Academic Publisher, Netherlands, 2001, pp. 323-342

[8] T. Kobayashi, J.W. Dally, Relation between crack velocity and the stress intensity factor in birefringent polymers, G.T. Hahn, M.F. Kanninen (Eds.), Fast Fracture and Crack Arrest, ASTM STP, vol. 627, 1977, pp. 257-273.

[9] J.W. Dally, A. Shukla, Energy loss in Homalite 100 during crack propagation and arrest, Eng. Fract. Mech. 13 (1980) 807-817.

[10] A. Shukla, H. Nigam, A note on the stress intensity factor and crack velocity relationship for Homalite 100, Eng. Fract. Mech. 25 (1986) 91-102.

[11] A.S. Kobayashi, M. Ramulu, M.S. Dadkhah, K.-H.Yang, B.S.J. Kang, Dynamic fracture toughness, Int. J. Fract. 30 (1986) 275-285.

[12] J.W. Dally, R.K. Agarwal, R.J. Sanford, A study of hysteresis in the $K_{\mathrm{ID}^{-}} \dot{a}$ relation, Exp. Mech. 30 (1990) 177-183.

[13] P.S. Theocaris, G.A. Papadopoulos, Elasto-dynamic forms of caustics for running cracks under constant velocity, Eng. Fract. Mech. 13 (1980) 683-698.

[14] J.F. Kalthoff, On some current problems in experimental fracture dynamics, in: W.G. Knauss (Ed.), Workshop on Dynamic Fracture, California Institute of Technology, Pasadena, 1983, pp.11-35.

[15] W.G. Knauss, K. Ravi-Chandar, Some basic problems in stress wave dominated fracture, Int. J. Fract. 27 (1985) 127-143.

[16] K. Takahashi, K. Arakawa, Dependence of crack acceleration on the dynamic stress intensity factor in polymers, Exp. Mech. 27 (1987) 195-200.

[17] F.G. Katsamanis, C.G. Delides, Fracture surface energy measurements of PMMA: a new experimental approach, Journal of Physics D: Applied Physics 21 (1988) 79-861.

[18] S. Suzuki, H. Homma, R. Kusaka, Pulsed holographic microscopy as a measurement method of dynamic fracture toughness for fast propagating cracks, J. Mech. Phys. Solids 36-6 (1988) 631-653.

[19] T. Nishioka, T. Murakami, H. Uchiyama, K. Sakakura, H. Kittaka, Specimen size effects on dynamic crack propagation and arrest in DCB specimens, Eng. Fract. Mech. 39 (1991) 757-767.

[20] K. Arakawa, K. Takahashi, Relationships between fracture parameters and fracture surface roughness of brittle polymers, Int. J. Fract. 48 (1991) 103-114.

[21] K. Arakawa, K. Takahashi, Branching of a fast crack in polymers, Int. J. Fract. 48 (1991) 245-259.

[22] K. Arakawa, D. Nagoh, K. Takahashi, Crack velocity and acceleration effects on the dynamic stress intensity factor in polymers, Int. J. Fract. 83 (1997) 305-313. 
[23] K. Arakawa, D. Nagoh, K. Takahashi, Dynamic crack propagation and unloading behavior of brittle polymers, Int. J. Fract. 96 (1999) 347-360 .

[24] K. Arakawa, T. Mada, K. Takahashi, Correlations among dynamic stress intensity factor, crack velocity and acceleration in brittle fracture, Int. J. Fract. 105 (2000) 311-320.

[25] K. Arakawa, T. Mada, Unsteady dynamic crack propagation in a brittle polymer, Exp. Mech. 47 (2007) 609-615.

[26] K. Arakawa, T. Mada, Measuring fracture energy in a brittle polymeric material, Exp. Mech. 46 (2006) 347-353.

[27] K. Arakawa, T. Mada, Measuring fracture energy in a brittle polymeric material, Application of a high-speed optical extensometer, Exp. Mech. 47 (2007) 211-216.

[28] K. Arakawa, T. Mada, S. D. Park, M. Todo, Tensile fracture behavior of a biodegradable polymer, poly(lactic acid), Polym. Test 25 (2006) 628-634.

[29] K. Arakawa, T. Mada, M. Todo, J. Takahashi, S. Ooka, Impact tensile fracture testing of a brittle polymer, Polym. Test 25 (2006) 1095-1100.

[30] K. Arakawa, T. Mada, M. Todo, J. Takahashi, S. Ooka, Effect of rubber particle size on the impact tensile fracture behavior of MBS resin with a bimodal particle size distribution, J. Mater. Sci. 42 (2007) 8700-8706. 


\section{Figure Captions}

Fig. 1 Specimen geometries: (a) composite resin, (b) PMMA.

Fig. 2 Experimental setup.

Fig. 3 Loading jigs used for the static test.

Fig. 4 Load $P$ versus displacement $\delta$.

Fig. 5 Displacement $\delta$ ' versus time $t$.

Fig. 6 Residual displacement $\delta_{\mathrm{n}}$ versus fracture load $P_{\mathrm{c}}$.

Fig. 7 Flying height $H_{\mathrm{e}}$ versus fracture load $P_{\mathrm{c}}$.

Fig. 8 Energy ratios $E_{\mathrm{e}} / U_{\text {ex }}$ and $E_{\mathrm{n}} / U_{\text {ex }}$ versus fracture load $P_{\mathrm{c}}$.

Fig. 9 Energy ratio $E_{\mathrm{f}} / U_{\mathrm{ex}}$ versus fracture load $P_{\mathrm{c}}$.

Fig. 10 Energy release rate $G_{\mathrm{f}}$ versus fracture load $P_{\mathrm{c}}$. 

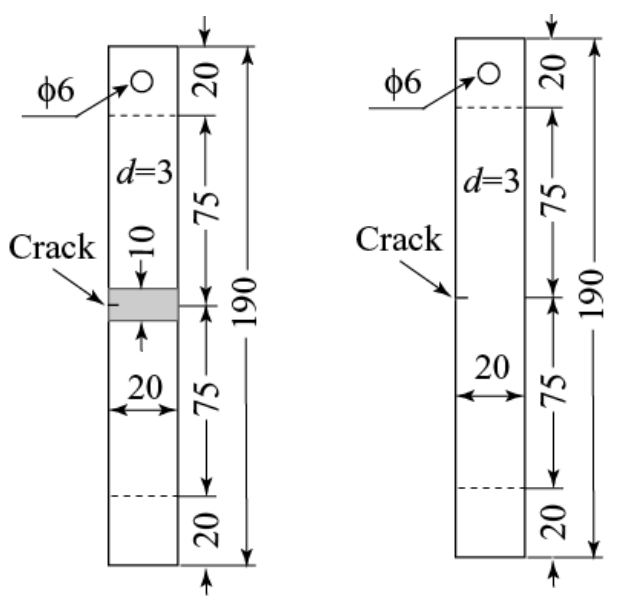

(a) composite resin (b) PMMA

Fig. 1 Specimen geometries.

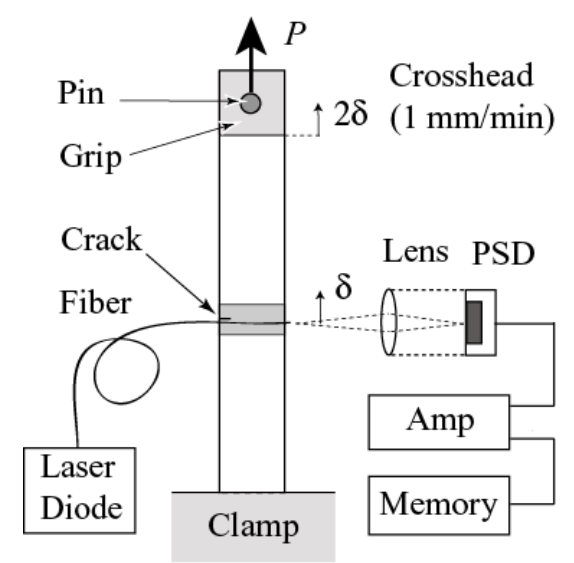

Fig. 2 Experimental setup.

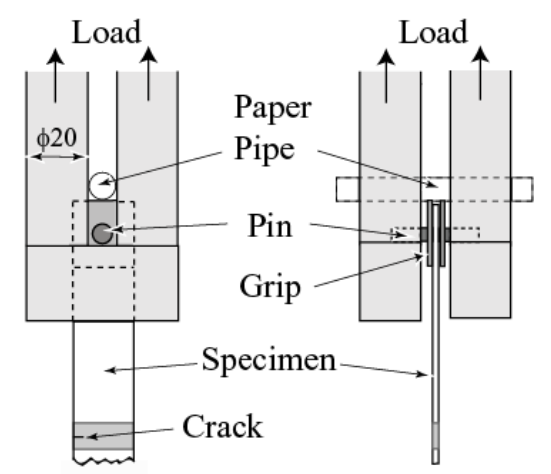

Fig. 3 Loading jigs used for the static test. 


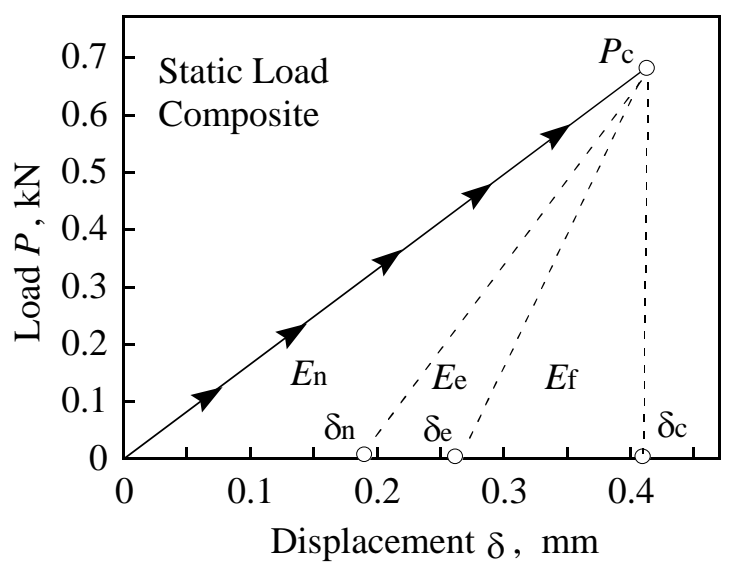

Fig. 4 Load $P$ versus displacement $\delta$.

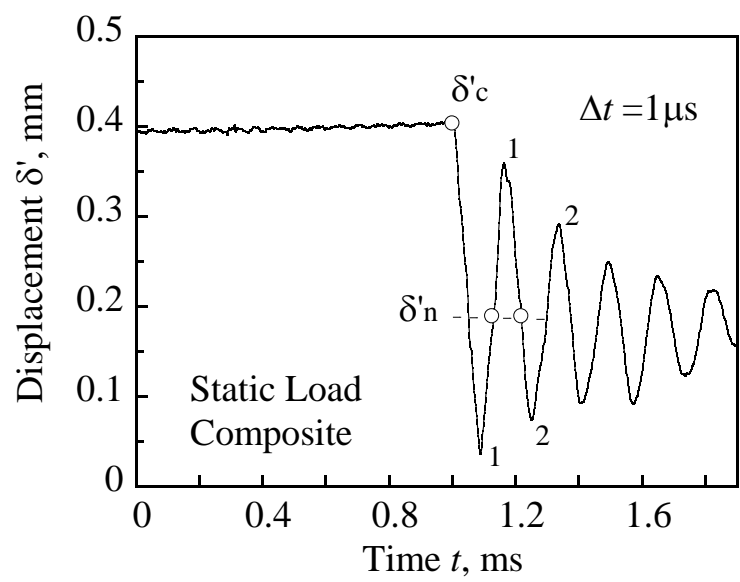

Fig. 5 Displacement $\delta$ ' versus time $t$.

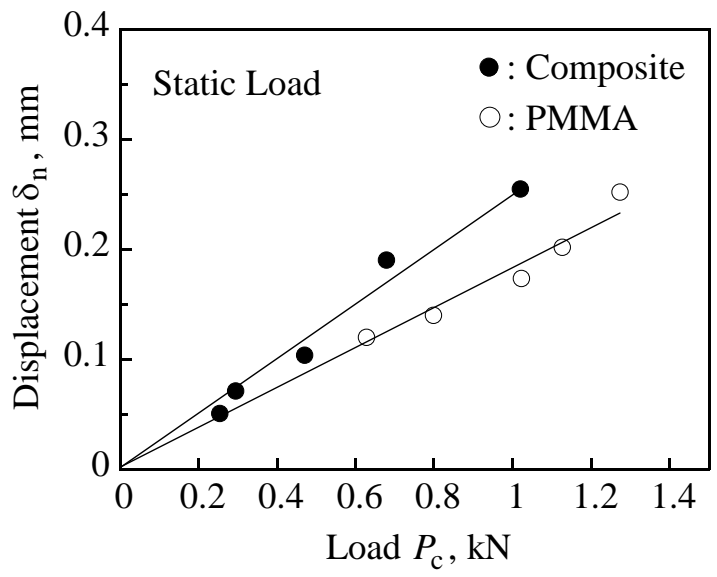

Fig. 6 Residual displacement $\delta_{\mathrm{n}}$ versus fracture load $P_{\mathrm{c}}$. 


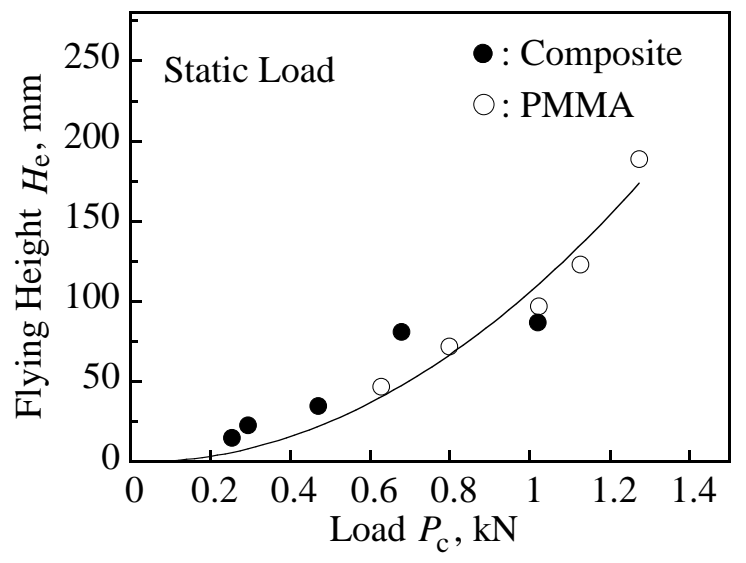

Fig. 7 Flying height $H_{\mathrm{e}}$ versus fracture load $P_{\mathrm{c}}$.

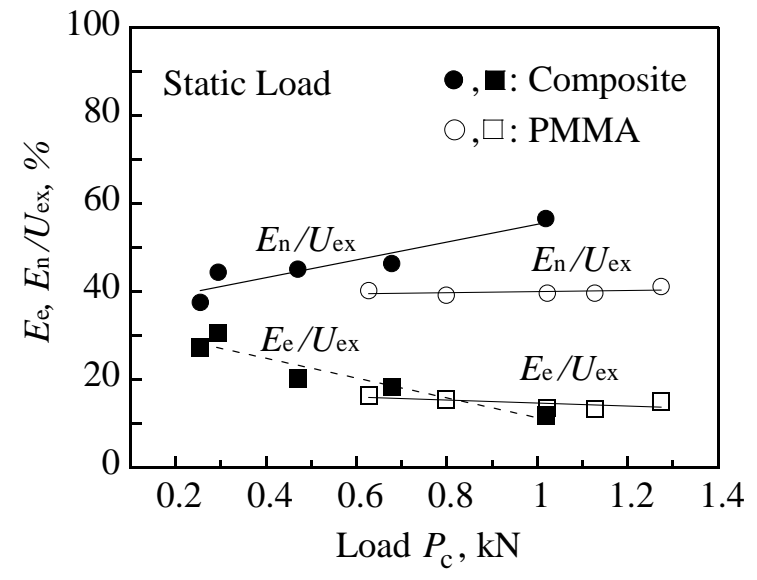

Fig. 8 Energy ratios $E_{\mathrm{e}} / U_{\text {ex }}$ and $E_{\mathrm{n}} / U_{\text {ex }}$ versus fracture load $P_{\mathrm{c}}$

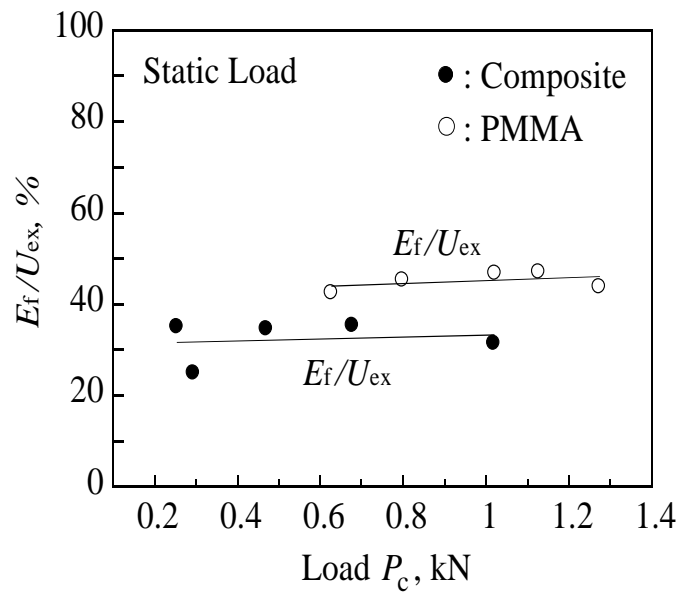

Fig. 9 Energy ratio $E_{\mathrm{f}} / U_{\text {ex }}$ versus fracture load $P_{\mathrm{c}}$. 


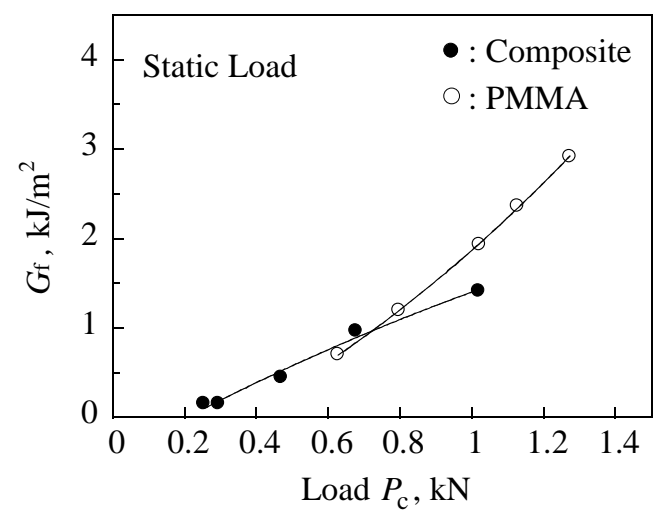

Fig. 10 Energy release rate $G_{\mathrm{f}}$ versus fracture load $P_{\mathrm{c}}$. 